\title{
Comparative Study on Wind Analysis of Multi-story RCC and Composite Structure for Different Plan Configuration
}

\author{
Shaikh Muffassir ${ }^{1}$, L.G. Kalurkar ${ }^{2}$ \\ I (PG Student, Department of civil Engineering, J.N.E.C, Aurangabad, Maharashtra, India) \\ ${ }_{2}^{2}$ (Assistant Professor, Department of civil Engineering, J.N.E.C, Aurangabad, Maharashtra, India)
}

\begin{abstract}
The multi story high rise RCC structures are more bulky and less ductile in nature as compare to composite structures. This study investigates the comparison between RCC and composite structure under the effect of wind, additional to it composite structure also includes different plan configurations. In this study total fifteen number of building model are prepared and analysis for wind load by using ETABS 2015. The wind analysis is performed for different heights such $20 \mathrm{~m}$, $50 \mathrm{~m}$ and $80 \mathrm{~m}$. In addition, the comparative study concludes that the composite structure are larger ductile in nature and more susceptible as compare to RCC structure and the composite option is better than RCC for multi story buildings. In addition, the comparison of different plan configuration shows that the response of parameter such as story displacement, story stiffness, base reaction and time period under effect of wind. The purpose of this analysis is to determine the most effective shape of structure in prone zone.
\end{abstract}

Keywords: Basic wind speed, Composite structure, Different plan configuration, RCC structure, Wind analysis.

\subsection{General}

\section{INTRODUCTION}

The reinforced concrete structures are mostly used from many decades because of its stiffness, most convenience, high durability and ease to construct. The RCC structures are more suitable for low rise structure but for medium to high rise structures it is no longer economical because of large dead load, less susceptible, span restriction and complex formwork. So that, Structural designer is facing the problem of less susceptibility to lateral loads and also the problem of economy. The population of India is increasing day by day and they required land for living, for that multi story structures are best option for construction in metropolis cities where less land is available. Because multi story structure provides large floor area in small land area. Therefore, it is essential to construct high rise buildings. If high rise buildings are constructed than many structural problems arise, such as lateral load effect, lateral displacement and stiffness etc. Generally for high rise structure wind and earth quake load effects are dominant. Therefore for high rise buildings it is essential to have knowledge of various loads and its effect on buildings. The effect of lateral load is very important to consider such as earthquake and wind loads. In some cases the wind load is dominant than earthquake load which depends on area and zone factor defined by codes. Defining wind there are two aspects first one is beneficial which is to generate power and gives relief in hot and humid atmosphere and second one is parasitic which comes out to be factor consider for engineers. This wind effect will cause and produce wind induced motion in the structure.

As high rise buildings push the envelope to greater heights, the structural designers are not only faced with problem to choosing a structural elements to carry the lateral load such as wind load and earthquake load but also insuring the design criteria that meets stability and serviceability requirement under complex wind environment. In addition, the high rise structures should meet more stiffness under lateral loads. Wind load act as lateral load on buildings which is act as along and across wind. In IS Code 875(Part 3)-1987, the basic wind speed are given in map and categorized by zones. The shape of buildings is very important in wind analysis, because the wind pressure is mainly depends on the exposed area of building against wind.

\subsection{Literature view}

Syed Fahad Ali and S.A. Bhalchandra [1]: Presented the work on seismic analysis of RCC and steelconcrete composite structure. The modeling and analysis of RCC and composite buildings has done by finite element based software ETABS 2015 and also buildings are categorized with number of stories. In addition, they also presented the cost comparison of RCC and composite structure with different support condition. From overall view of analysis and result, they suggest that the composite structures are more economical than RCC structure and the composite structures are better option for multi story buildings to resist the seismic loads. 
D.R. Panchal and P.M Marathe [2]: Presented the comparative study of RCC, steel and composite $(\mathrm{G}+30)$ stories structures under the seismic effect. For the analysis equivalent static method has been used and modeling of structures has done by ETABS. And also the result has computed from ETABS. From this study they conclude that the steel structures are better than RCC structures for low rise buildings but for high rise buildings the composite option is best suited among all three options. In addition, the reduction in self weight of steel structure is $32 \%$ less than RCC structures and the self weight of composite structure is $30 \%$ less than RCC structures. And also they suggest that, in steel structure the bending moment of secondary beam increased by average $83.3 \%$ and reduced by $48 \%$ in composite structure as compare to RCC.

Sanhik Kar Majumder and Priyabrata Guha [3]: Presented the comparison between wind and seismic load on different types of structures. In this study, the effect of wind and seismic both will be considered and compared them according to IS 875(Part 3)-1987 and IS 1893(Part 1)-2002. The modeling and analysis of $(\mathrm{G}+5)$ structures are done by using STAAD Pro. They compare results of bending moment due to wind and earthquake loads. After analysis and result they conclude that, the bending moment due to earthquake loads are greater than bending moment due to wind loads.

Abhay Guleria [4]: Presented the analysis of multi story RCC building for different plan configuration. The analysis has performed for the earthquake loads. The specification of lateral loads has been taken from IS 1893 (Part 1)-2002. The modeling and analysis has done by using finite element based software ETABS. From the analysis and results, they conclude that the effect of shape is very important. And also they compare the result of different plan configuration buildings such as story shear, overturning moment, story drift, story displacement and mode shapes. In addition, this study suggests that L-shape and Ishape structure gives almost similar response against overturning moment, story drift, and Story displacement.

\subsection{Objective}

The primary objective of this study is to determine the most effective shape under complex wind environment and also to determine the effective structure between RCC and Composite. This paper overviews the entire effect of wind on high rise structure and detailed study of current challenges due to wind. In addition, this paper discusses to predict the wind pressure and forces on actual buildings with different shapes and also performed the wind analysis of building for different plan configuration for estimating wind load effect on high rise structure.

In this paper work, steel-concrete composite has used instead of RCC and compare both for different parameter such as, story displacement, story stiffness, base reaction, maximum bending moment in columns and time period. Wind analysis has performed for different story of composite buildings such as $(\mathrm{G}+5)$, $(\mathrm{G}+15)$ and $(\mathrm{G}+25)$ and also for different plan configuration. In this study the composite structure has used because the composite column made up concrete encased hot rolled steel section which increased strength for a given cross section dimension, stiffness and susceptible to lateral loads. In addition, the composite beam mainly subjected to bending and is a composite of steel section and concrete deck. Due to high susceptible and ductility of steel material it leads to effective in wind load resistance. The main purpose of this study, to perform the wind analysis of composite structure and estimating the parameter for wind load effect.

\section{SYSTEM DEVELOPMENT}

A composite building having plan dimension $15 \mathrm{X} 15 \mathrm{~m}$ in square shape and RCC building having plan dimension $15 \mathrm{X} 15 \mathrm{~m}$ in square shape has taken for comparative study. For this study different number of stories consider such as $(\mathrm{G}+5),(\mathrm{G}+15)$ and $(\mathrm{G}+25)$. Each bay of building $5 \mathrm{X} 5 \mathrm{~m}$ and having each story height $3 \mathrm{~m}$. Same plan dimension and number of stories has taken for $\mathrm{H}$ shape, $\mathrm{U}$ shape and rectangular composite buildings. The thickness of slab and deck has taken $150 \mathrm{~mm}$ for both structures. The dimensions of column and beam are mentioned in Table 3, 4, 5, 6, 7, and Table 8.

For this analysis various loads are considered such as dead load, live load and wind load respectively. The combination of loads consider according to IS 875(Part 5)-1987. The various loadings are mentioned in Table 9. 


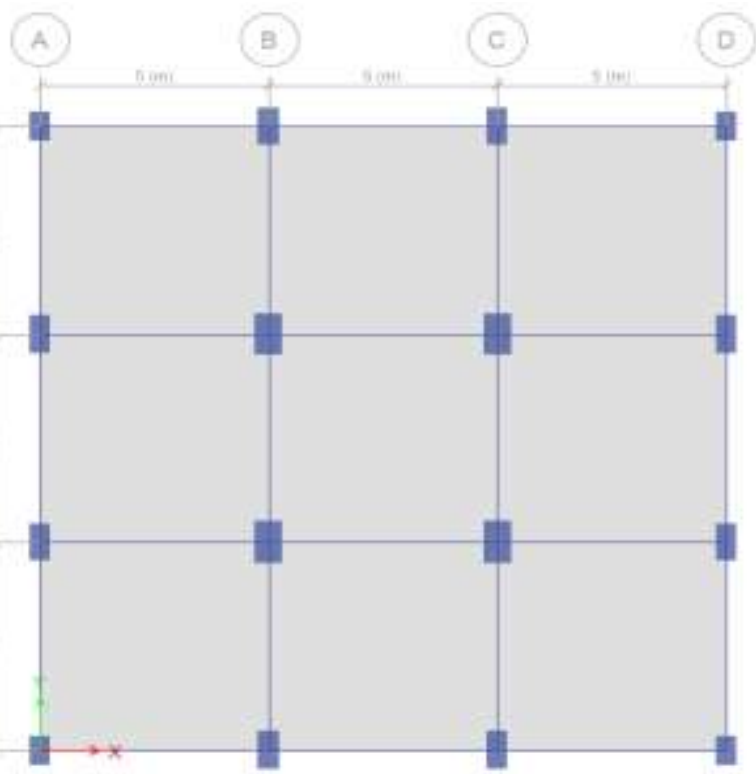

Fig. 1 Plan view of Square building
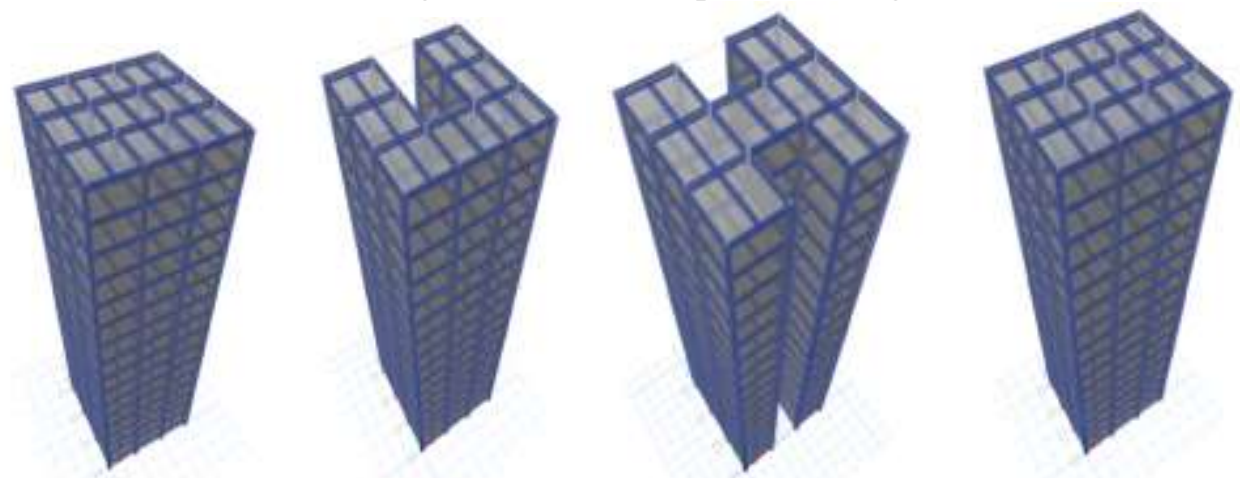

Fig. 2 3D View of Square, U-Shape, H-Shape, Rectangular building

Table 1: Material Properties

\begin{tabular}{|l|c|}
\hline Grade of Concrete & M25 \\
\hline Grade of Reinforcing steel & Fe 500 \\
\hline Grade of Structural steel & Fe 345 \\
\hline Density of Concrete & $25 \mathrm{KN} / \mathrm{m}^{3}$ \\
\hline Density of Brick masonry & $20 \mathrm{KN} / \mathrm{m}^{3}$ \\
\hline Damping ratio & $5 \%$ \\
\hline
\end{tabular}

Table 2: General Specification of Building

\begin{tabular}{|c|c|}
\hline Plan dimension & $15 \mathrm{~m} \mathrm{X} \mathrm{15m}$ \\
\hline$(\mathrm{G}+5)$ & $20 \mathrm{~m}$ \\
\hline$(\mathrm{G}+15)$ & $50 \mathrm{~m}$ \\
\hline$(\mathrm{G}+25)$ & $80 \mathrm{~m}$ \\
\hline Storey Height & $3 \mathrm{~m}$ \\
\hline Thickness of deck/slab & $150 \mathrm{~mm}$ \\
\hline Thickness of wall & $230 \mathrm{~mm}$ \\
\hline
\end{tabular}

Table 3: Specification of $(\mathrm{G}+5)$ RCC Building Table 4: Specification of $(\mathrm{G}+5)$ Composite Building

\begin{tabular}{|c|c|}
\hline RCC & Section \\
\hline Beam & 230 X 600 \\
\hline Column 1 & $300 \times$ X 700 \\
\hline Column 2 & 300 X 550 \\
\hline Column 3 & 230 X 600 \\
\hline
\end{tabular}

\begin{tabular}{|c|c|c|}
\hline Composite & Section & Encased Section \\
\hline Beam & ISWB 300 & - \\
\hline Column 1 & 350 X 650 & ISMB 500 \\
\hline Column 2 & $300 \times$ X 500 & ISMB 350 \\
\hline Column 3 & $300 \times 400$ & ISWB 225 \\
\hline
\end{tabular}


Table 5: Specification of (G+15) RCC Building Table 6: Specification of $(\mathrm{G}+15)$ Composite Building

\begin{tabular}{|c|c|}
\hline RCC & Section \\
\hline Beam & $300 \times 600$ \\
\hline \multicolumn{2}{|c|}{ Column up to 9 story } \\
\hline Column 1 & $600 \times 1000$ \\
\hline Column 2 & $450 \times 900$ \\
\hline Column 3 & $480 \times 700$ \\
\hline Column from 10 to 17 story \\
\hline Column 4 & $450 \times 900$ \\
\hline Column 5 & $480 \times 700$ \\
\hline Column 6 & $350 \times 700$ \\
\hline
\end{tabular}

\begin{tabular}{|c|c|c|}
\hline Composite & Section & Encased Section \\
\hline Beam & ISWB 550 & - \\
\hline \multicolumn{3}{|c|}{ Column up to 9 story } \\
\hline Column 1 & $600 \times 900$ & ISWB 600-2 \\
\hline Column 2 & $450 \times 900$ & ISWB 600-2 \\
\hline Column 3 & $450 \times 700$ & ISWB 550-1 \\
\hline \multicolumn{3}{|c|}{ Column from 10 to 17 story } \\
\hline Column 4 & $450 \times 700$ & ISWB 550-1 \\
\hline Column 5 & $350 \times 700$ & ISMB 550 \\
\hline Column 6 & $350 \times 650$ & ISMB 500 \\
\hline
\end{tabular}

Table 7: Specification of $(\mathrm{G}+25)$ RCC Building

\begin{tabular}{|c|c|}
\hline RCC & Section \\
\hline Beam & 400 X 650 \\
\hline \multicolumn{2}{|c|}{ Column up to 14 story } \\
\hline Column 1 & $800 \times 1200$ \\
\hline Column 2 & $600 \times 1000$ \\
\hline Column 3 & $450 \times 900$ \\
\hline \multicolumn{2}{|c|}{ Column from 15 to 27 story } \\
\hline Column 4 & $600 \times 1000$ \\
\hline Column 5 & $450 \times 900$ \\
\hline Column 6 & $450 \times 700$ \\
\hline
\end{tabular}

Table 8: Specification of $(\mathrm{G}+\mathbf{2 5})$ Composite Building

\begin{tabular}{|c|c|c|}
\hline Composite & Section & Encased Section \\
\hline Beam & W 18X311 & - \\
\hline \multicolumn{3}{|c|}{ Column up to 9 story } \\
\hline Column 1 & $600 \times 1200$ & W40X277 \\
\hline Column 2 & $600 \times 900$ & W27X235 \\
\hline Column 3 & $450 \times 900$ & W27X102 \\
\hline \multicolumn{3}{|c|}{ Column from 10 to 17 story } \\
\hline Column 4 & $450 \times 900$ & W27X102 \\
\hline Column 5 & $480 \times 700$ & W18X143 \\
\hline Column 6 & $350 \times 700$ & W 21X55 \\
\hline
\end{tabular}

Table 9: Specification of Loading

\begin{tabular}{|c|c|}
\hline Floor load & $1 \mathrm{KN} / \mathrm{m}^{2}$ \\
\hline Live load & $4 \mathrm{KN} / \mathrm{m}^{2}$ \\
\hline Wall load & $12 \mathrm{KN} / \mathrm{m}^{2}$ \\
\hline Basic wind speed & $50 \mathrm{~m} / \mathrm{s}$ \\
\hline Risk coefficient (K1) & 1 \\
\hline Topography factor (K3) & 1 \\
\hline Wind design code & IS $875: 1987$ (Part 3) \\
\hline RCC design code & IS $456: 2000$ \\
\hline Steel design code & IS 800:2007 \\
\hline Composite design code & AISC-360-10 \\
\hline
\end{tabular}

\section{RESULT AND DISCUSSION}

The modelling and analysis of both RCC and Composite buildings has been done in finite element based software ETABS. For the comparative study total fifteen number of RCC and composite structures has been modeled. The parameter such as, story displacement, story stiffness, base reaction, maximum bending moment and time period has evaluated from ETABS. For the anlysis of composite structure AISC 360-10 code has been used. The basic wind speed $(\mathrm{Vb})$, external pressure coefficient $(\mathrm{Cpe})$ and internal pressure coefficient (Cpi) has computed from Indian standard code IS 875(Part 3) -1987.

\subsection{Story Displacement}

The story displacement for $(\mathrm{G}+5),(\mathrm{G}+15)$ and $(\mathrm{G}+25)$ has been evaluated for RCC and Composite structure. The story displacement has been shown in Figures below. The below graph show that displacement are varies with increase in height. The displacemnt of composite structure is greater than the RCC structure. Similarly the displacement of U-shape Composite building is greater than sqaure, rectangular and $\mathrm{H}$-shape buildings. 


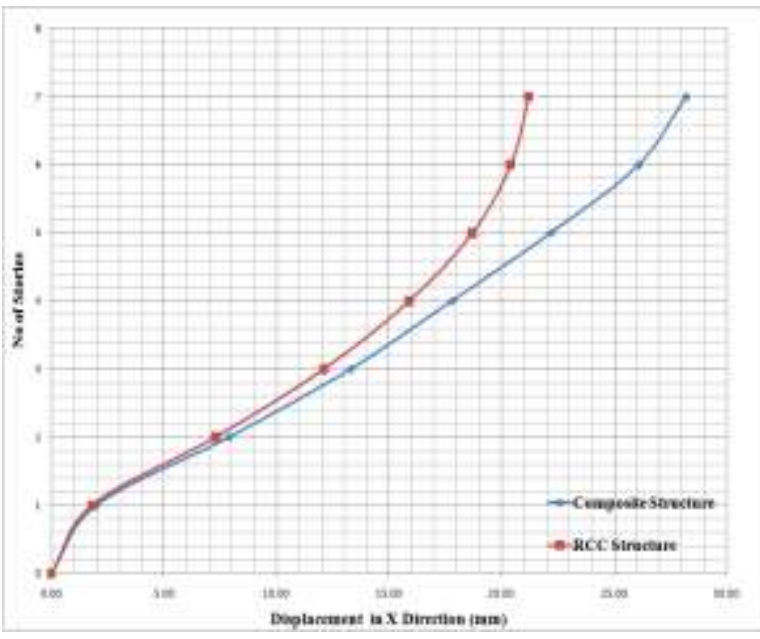

Fig. 3 Story Displacement for $(\mathbf{G + 5})$

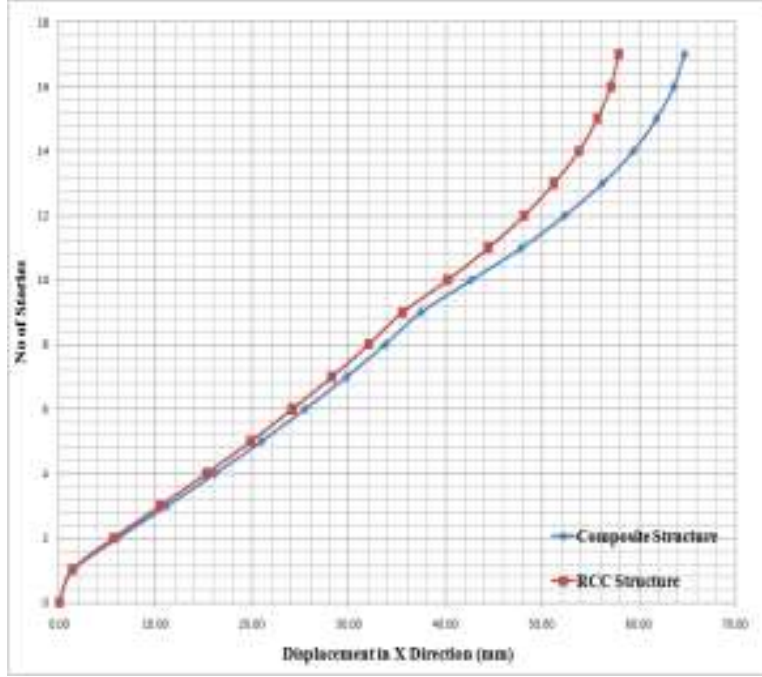

Fig. 5 Story Displacement for $(\mathbf{G + 1 5})$

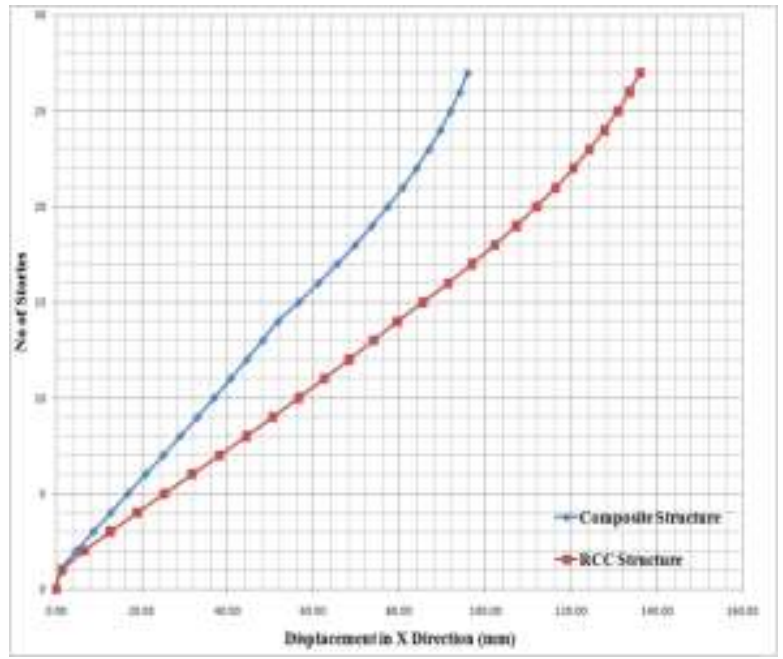

Fig. 7 Story Displacement for $(\mathbf{G}+25)$

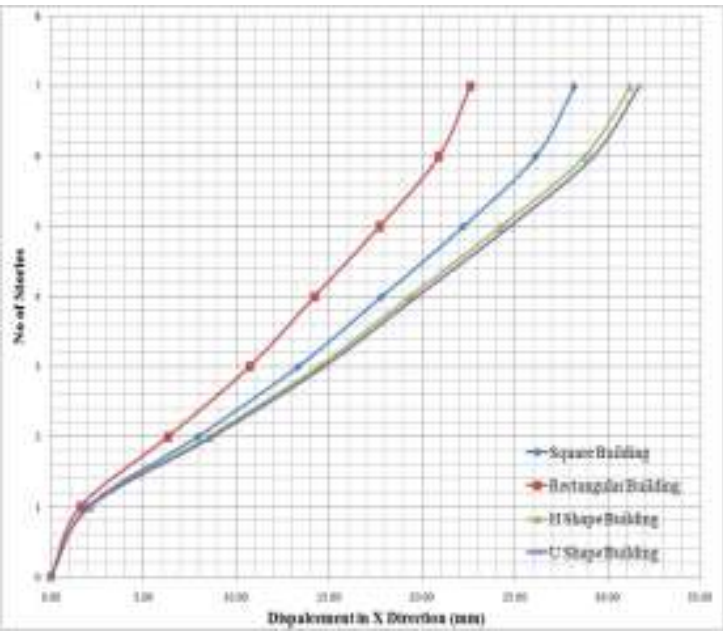

Fig. 4 Story Displacement for $(\mathbf{G + 5})$

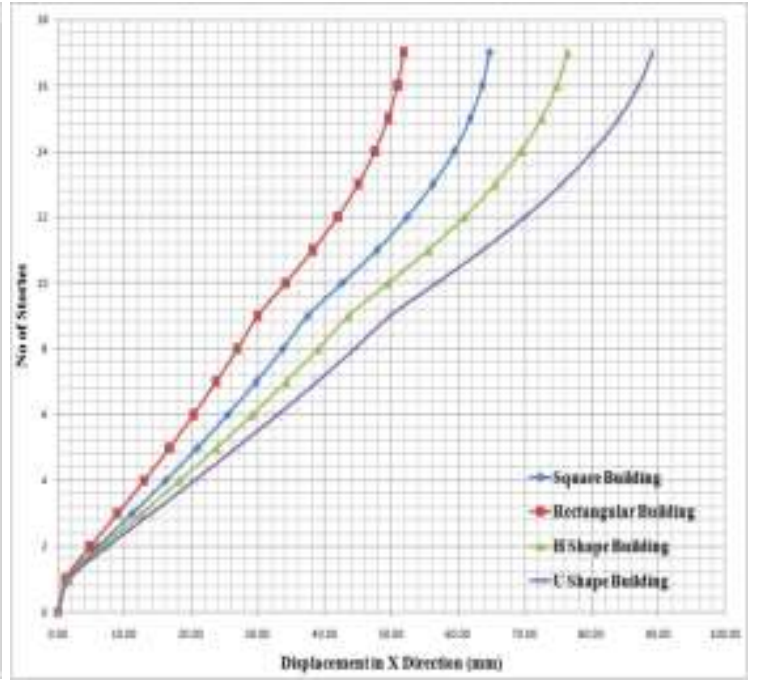

Fig. 6 Story Displacement for $(G+15)$

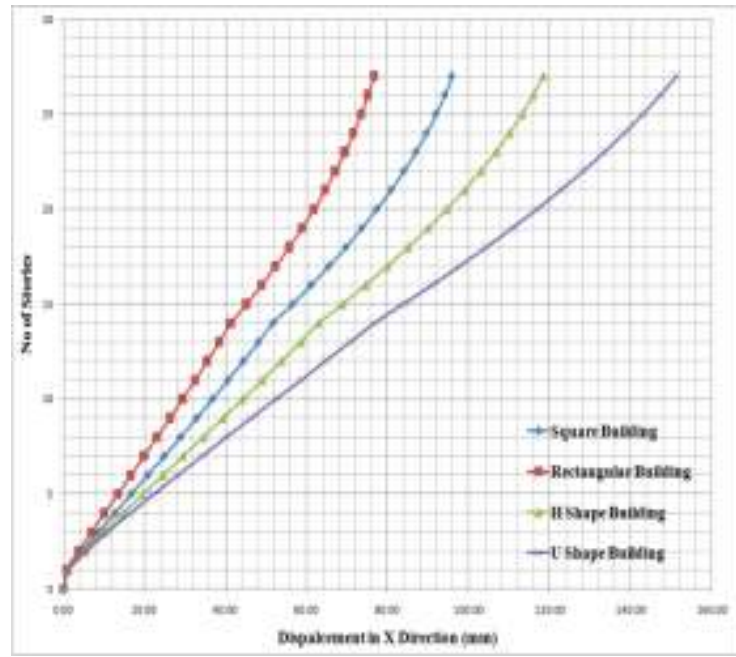

Fig. 8 Story Displacement for $(G+25)$ 


\subsection{Base reaction}

The base reaction has been evaluated for RCC and Composite structures for 1.5(DL+LL) load combination. The following figures 9 and 10 shows the comparison of base reaction of RCC and composite structures and also the comparison of different shapes of composite structure. The figure 9 and 10 show that the base reaction of RCC structure is maximum as compare to composite structure. Similarly the base reaction of square shape of composite building is maximum as compare to other shapes of composite building.

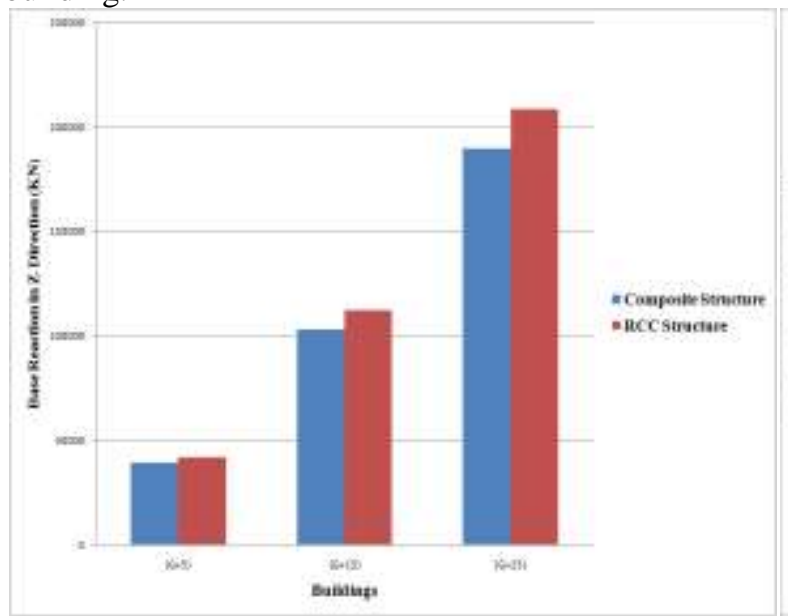

Fig. 9 Base Reaction of Buildings

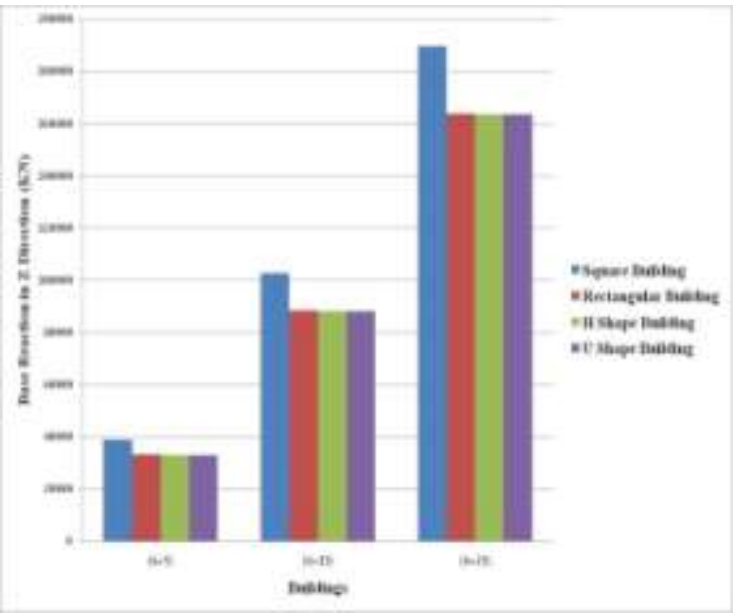

Fig. 10 Base Reaction of Buildings

\subsection{Comparison of Maximum bending moment in columns}

The maximum bending moment in columns has been evaluated for RCC and composite structure for different number of stories and also for different shape of composite buildings. The figure 11 suggest that the maximum bending moment in columns of RCC structure is more than composite structure, but figure 12 shows that the maximum bending moment in columns of $\mathrm{H}$ - shape Composite building increases with increase in number of stories and height of structure. The maximum bending moment in columns has been evaluated for comparison of RCC and composite structure.

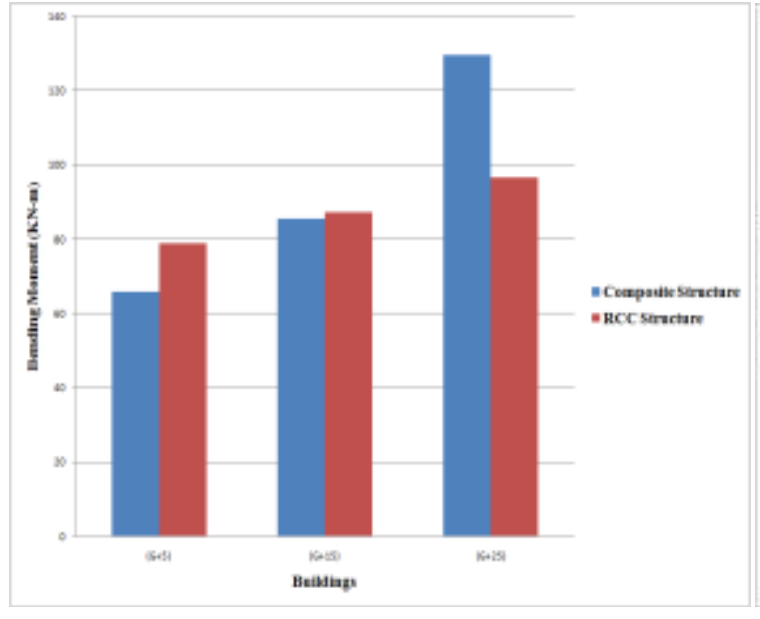

Fig. 11 Maximum Bending Moment in Columns

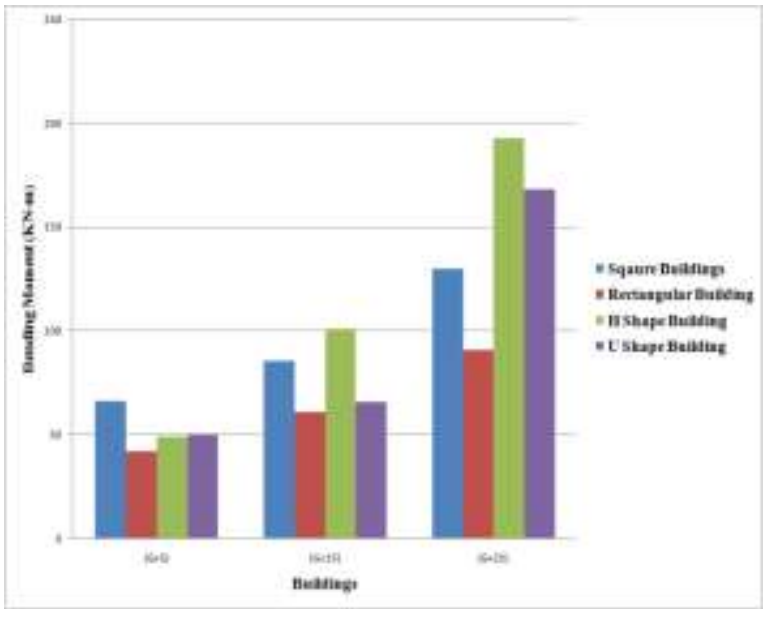

Fig. 12 Maximum Bending Moment in Columns

\subsection{Story stiffness}

The following figure 13 shows that the maximum story stiffness of RCC and composite structure and figure 14 shows the maximum story stiffness of different shape of composite buildings. From figure 13 it is observed that the stiffness of RCC structure is greater than the composite structure but for $(\mathrm{G}+25)$ building the stiffness of RCC structure is slightly less than Composite structure. From figure 14 it is clearly observed that square shape composite building has maximum value of stiffness compared to $\mathrm{H}$-shape and $\mathrm{U}$-shape buildings but rectangular building gives nearly same values of stiffenss. 


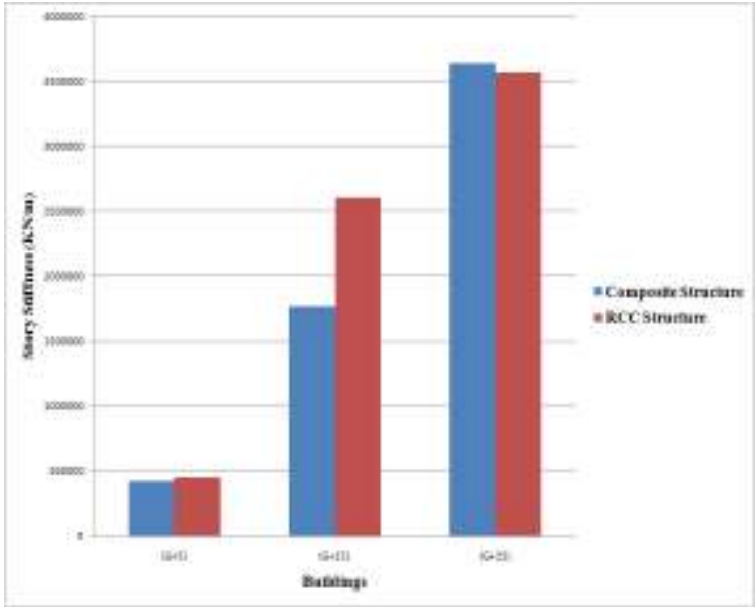

Fig. 13 Story Stiffness of Buildings

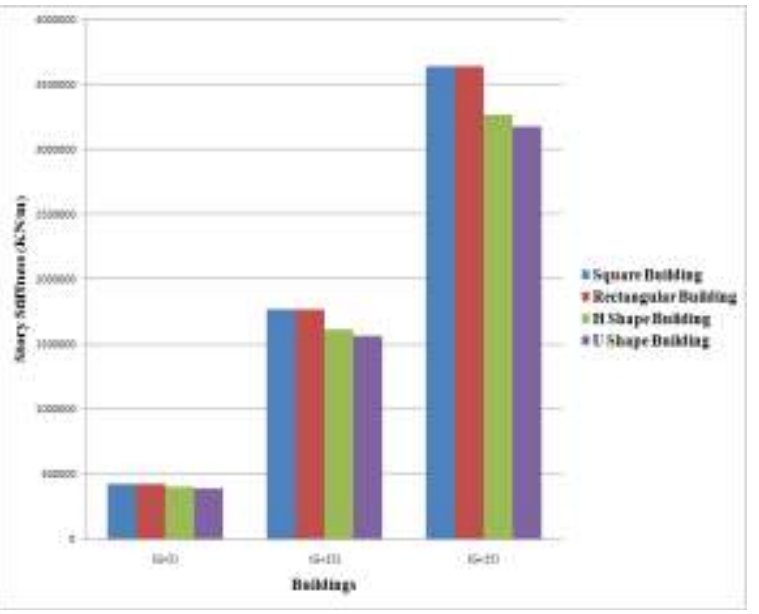

Fig. 14 Story Stiffness of Buildings

\subsection{Time period}

The time period of $(\mathrm{G}+5),(\mathrm{G}+15)$ and $(\mathrm{G}+25) \mathrm{RCC}$ and composite structures has shown in figure 15,16 and 17. The time period of RCC and Composite structures has been evaluated for different number of modes from ETABS. It is observed that the time period of composite structure is greater than the RCC structure for $(\mathrm{G}+5)$ buildings but for $(\mathrm{G}+15)$ and $(\mathrm{G}+25)$ buildings, the time period of RCC structure is greater than the composite structure. In mode one the maximum value of time period achieved. Also from following figures, it is observed that the time period increases with increase in height of building.

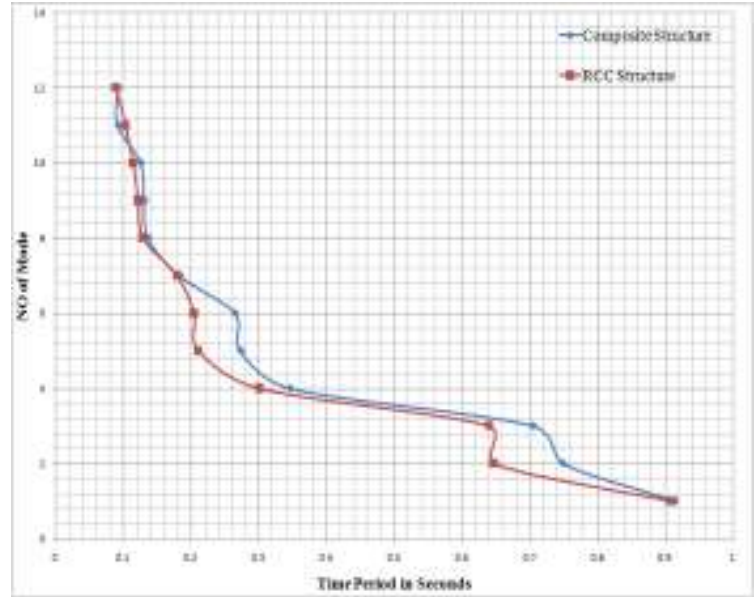

Fig. 15 Time Period of $(\mathbf{G + 5})$

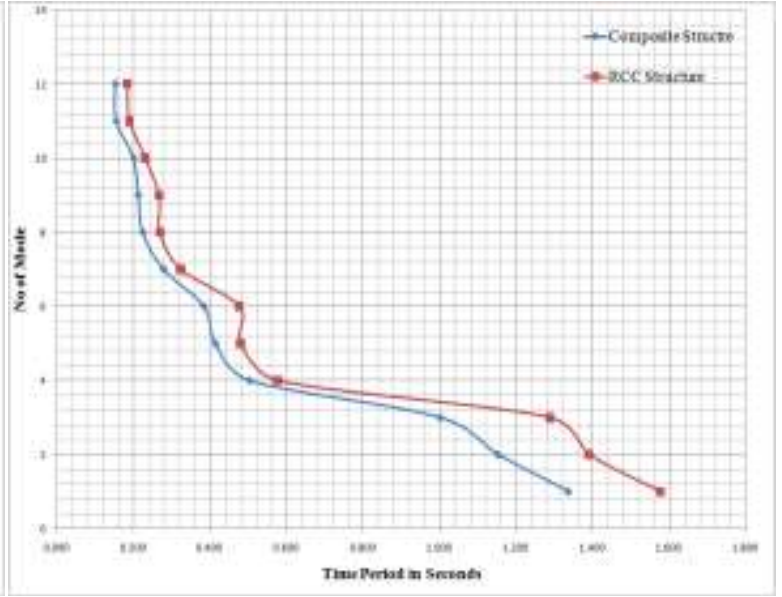

Fig. 16 Time Period of $(G+15)$

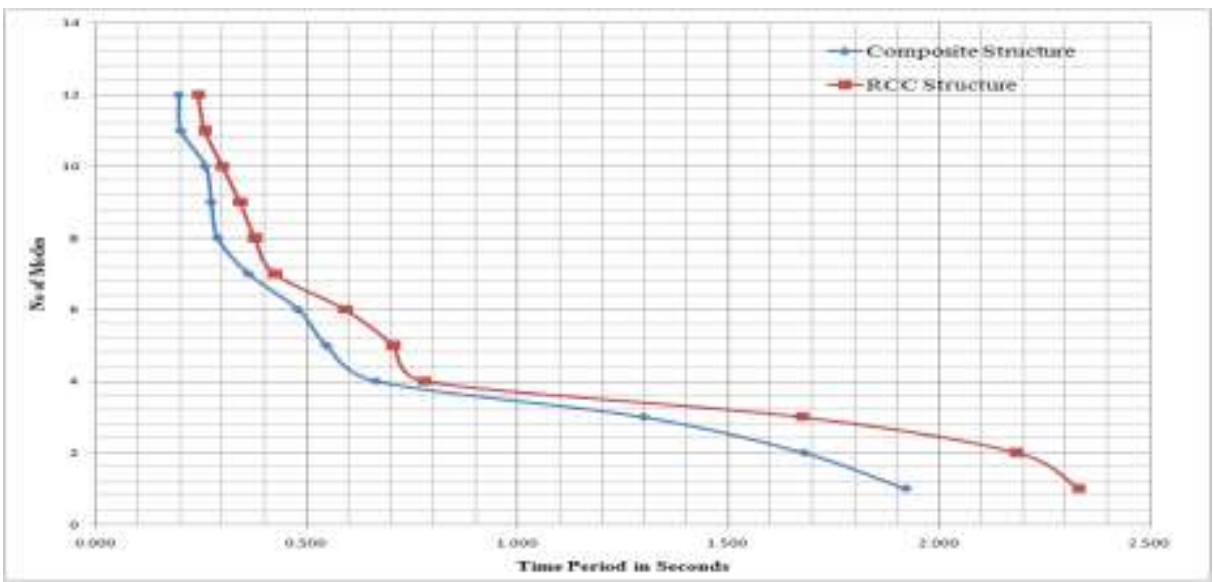

Fig. 17 Time Period of $(\mathbf{G + 2 5})$ 


\section{CONCLUSION}

This comparative study presented an assessment of wind load effect on multi story RCC and composite structure and also the different shape of composite structure. By observing the overall analysis result, graphs and bar charts of RCC and composite structure and comparing parameters, following conclusion can be made:

- The comparative study conclude that the composite structure are larger ductile in nature as compare to RCC structure and having parameters within acceptable limit.

- Composite structure are more susceptible to wind effect than the RCC structure therefore composite structure are preferable for wind prone zone.

- Composite structure provides large space for utilization and economical with high durability and rapid erection.

- The parameter study show that the effect of wind load on multi story structure is accountable for high rise structure and also depends on shape of buildings.

- The study of different shape of composite structure conclude that H-shape and U-shape type buildings gives almost same response for $(\mathrm{G}+5)$ building but however at $(\mathrm{G}+15)$ and $(\mathrm{G}+25)$ the parametric response of U-shape buildings abruptly changes as compare to other shapes.

- The result of different shape of composite buildings suggest that the rectangular shape building is more preferable in wind prone zone compare to other shape buildings.

- U-shape buildings is not preferable in wind prone zone due to large dispalcement and less stiffness.

\section{REFERENCES}

[1] Syed Fahad Ali and S.A. Bhalchandra, Study on seismic Analysis of RCC and steel-concrete composite structure and cost comparison with different support condition, International journal for scientific research and development, 3(9), 2015, 354-359.

[2] D.R. Panchal and P.M. Marathe, Comparative Study of RCC, steel and composite (G+30 storey) building, Institute Of Technology, Nirmal University, Ahmadabad, December, 2011, 08-10.

[3] Sanhik Kar Majumder and Priyabrata Guha, Comparison between wind and seismic load on different types of structures, International journal of engineering science invention, 3(4), 2014, 42-54.

[4] Abhay Guleria, Structural Analysis of a Multi story buildings using ETABS for Different plan configuration, International journal of engineering research and technology, 3(5), 2014, 1481-1485.

[5] Dae Kun Kwon and Ahsan Kareem, Wind load factors for dynamically sensitive structures with uncertainties, Engineering structures (ELSEVIER), 10(3), August 2015, 53-62.

[6] U.Y.Jeong, Advance in tall building design under strong winds, Structural congress ASCE, 2015, 2643-2654

[7] Luisa Pagnini, Reliability analysis of wind-excited structures, Journal of wind engineering and industrial aerodynamics (ELSEVIER), 98, 2010, 1-9.

[8] Tsuyoshi Nozu and Tetsuro Tamura, Mesh-adaptive LES for wind load estimation of a high-rise building in a city, Journal of wind engineering and industrial aerodynamics (ELSEVIER), 144, 2015, 62-69.

[9] Mahesh Suresh Kumawat and L.G.Kalurkar, Analysis and design of multi story building using composite structure, International Journal of Research in Engineering and Technology,3(2), 2014, 125-137.

[10] IS: 456(2000), Indian Standard Code of Practice for Plan and Reinforcement concrete (Fourth Revisions), Bureau of Indian Standards (BIS), New Delhi.

[11] IS: 875(Part 3)-1987, Indian Standard Code of Practice for Design loads (other than Earthquake) for Buildings and Structures, Bureau of Indian Standards, New Delhi.

[12] ANSI/AISC 360-10, Specification for Structural Steel Buildings, American Institute of Steel Construction, Chicago.

[13] IS 11384:1985, Code of Practice for Design of Composite Structure, Bureau of Indian Standards, New Delhi.

[14] R.P. Johnson, Composite Structures of Steel and Concrete Beams, Slabs, Columns and Frames for Buildings (Third Edition). 